\title{
Lower-Limb Muscle Strength, Anterior-Posterior and Inter-Limb Asymmetry in Professional, Elite Academy and Amateur Soccer Players
}

\author{
by \\ Marco Beato ${ }^{1}$, Damien Young ${ }^{2}$, Adam Stiff', Giuseppe Coratella ${ }^{3}$
}

Given the importance of the lower-limb strength and strength balance in soccer players and its relationship with injury prevention and performance, the present study compared quadriceps and hamstrings strength, the conventional ( $H_{\text {conc: }} Q_{\text {conc }}$ ), functional ( $H_{\text {ecc: }} Q_{\text {conc }}$ ) hamstrings-to-quadriceps ratio and inter-limb strength asymmetry in professional, elite academy and amateur male soccer players. In this cross-sectional study, two hundred-six soccer players (professional $=75$, elite academy $=68$, amateurs $=63$ ) volunteered to participate. Quadriceps and hamstrings isokinetic peak torque was investigated at $60^{\circ} \mathrm{S}^{-1}$ in both the concentric and eccentric modality and at $300^{\circ} \mathrm{S}^{-1}$ in the concentric modality. The conventional Hconc:Qconc, functional $H_{\text {ecc: }} Q_{\text {conc }}$ ratio and quadriceps and hamstrings inter-limb strength asymmetry were then calculated. Professional players presented greater quadriceps and hamstrings strength than elite academy (effect size from small to moderate) and amateur players (moderate to very large). Both the conventional $H_{c o n c}: Q_{c o n c}$ and functional $H_{\text {ecc: }} Q_{\text {conc }}$ ratio were greater in professional than elite academy and amateur players (small to moderate). Overall, quadriceps and hamstrings inter-limb strength asymmetry was greater in amateurs than professional (small to very large) and elite academy (trivial to large) players. The present findings provide coaches and medical staffs with normative lower-limb muscle strength data on professional, academy and amateur soccer players. Overall lower-limb muscle strength and inter-limb strength asymmetry could be used to evaluate possible inference on injury prevention and performance. The hamstrings-to-quadriceps ratio poorly differentiates between the soccer players background and offers limited prediction for injury prevention and performance.

Key words: isokinetic, knee flexors, hamstrings-to-quadriceps ratio, injury prevention.

\section{Introduction}

Soccer players perform specific activities such as jumps, sprints, changes of direction (COD) and technical actions (e.g.: shots, passes, etc.), which demand fast and powerful movements, involving lower-limb muscles in maximal and rapid actions (Rodriguez-Rosell et al., 2017). Among the lower-limb muscles, quadriceps and hamstrings have a crucial anatomical and biomechanical role in the knee and hip joint and are mostly involved during jumps, sprints, COD and kicks (Comfort et al., 2014). Since previous studies have found a positive correlation between quadriceps and hamstrings strength and soccer-related abilities (Chaouachi et al., 2012; Comfort et al., 2014; Morin et al., 2015; Wisløff et al., 2004), a periodic quadriceps and hamstrings strength screening may provide coaches and conditioners with useful information about the soccer players' fitness level. In addition to quadriceps and hamstrings strength, soccer players may benefit from a

\footnotetext{
1 - School of Health and Sports Sciences, University of Suffolk, Ipswich, UK.

2 - Research Unit EA3920 Prognostic Markers and Regulatory Factors of Cardiovascular Diseases and Exercise Performance, Univ. Bourgogne Franche-Comté, Besançon, France.

3 - Department of Biomedical Sciences for Health, Università degli Studi di Milano, Italy.
} 
balance in anterior/posterior muscle strength, usually defined as a hamstrings-to-quadriceps ratio (Baroni et al., 2018). Particularly, the relative hamstrings strength weakness might have repercussion on the anterior cruciate ligament safety (Weiss and Whatman, 2015) and represents a co-factor for the hamstrings strain injury occurrence (Green et al., 2018). The hamstrings-toquadriceps ratio is commonly assessed with an isokinetic dynamometer, considered as the "gold standard" for such an evaluation since it provides a controlled environment in which the neuromuscular performance of the joint system can be stressed maximally (Impellizzeri et al., 2008). To monitor the strength balance between hamstrings and quadriceps, the conventional $\mathrm{H}_{\text {conc: }} \mathrm{Q}_{\text {conc }}$ ratio was first established, in which concentric strength of both hamstrings and quadriceps was evaluated (Heiser et al., 1984). However, since hamstrings and quadriceps do not act simultaneously in a concentric modality, the functional $\mathrm{H}_{\text {ecc: }} \mathrm{Q}_{\mathrm{conc}}$ ratio has been proposed later, in which hamstrings strength is measured eccentrically (Orchard et al., 1997). It was suggested that a conventional $\mathrm{H}_{\text {conc: }} \mathrm{Q}_{\text {conc }}$ ratio lower than 0.55 (Croisier et al., 2008) and a functional Hecc:Qconc ratio lower than 0.7 (Rahnama et al., 2003) may theoretically result in an increased risk of a hamstrings strain injury. Notwithstanding, this was not further supported, since a recent meta-analysis showed that low conventional $\mathrm{H}_{\text {conc: }} \mathrm{Q}_{\mathrm{conc}}$ and functional $\mathrm{H}_{\mathrm{ecc}}: \mathrm{Q}_{\mathrm{conc}}$ ratios were not predictors of the hamstrings strain injury (Green et al., 2018). However, hamstrings injury is a multi-factorial event accounted for several factors (e.g. injury history, age, poor eccentric strength, training load) (Ekstrand et al., 2016; Hägglund et al., 2013; Malone et al., 2019), thus lower-limb muscle strength could be useful to monitor possible risk factors.

The inter-limb muscle strength asymmetry is defined as the relative strength difference between limbs (Thomas et al., 2017). An inter-limb strength screening may provide useful information about the injury risk and performance. Indeed, it was reported that injury frequency increased in athletes with quadriceps inter-limb asymmetry of $10 \%$ or more (Jeon et al., 2016). Similarly, in professional soccer players, an inter-limb asymmetry in quadriceps and hamstrings maximal strength indicated a reduced muscle function and an increased risk of injury (Hägglund et al., 2013). Additionally, quadriceps and hamstrings inter-limb strength asymmetry was negatively correlated with COD and sprinting ability (Coratella et al., 2018b).

The players' playing level and age were proposed to affect lower-limb muscle strength and asymmetry, suggesting monitoring it over the players' career evolution (Carvalho et al., 2016). Generally, amateur players reported lower quadriceps and hamstrings concentric and eccentric peak torque, as well as lower strength ratios in both lower-limbs compared to professional players (Carvalho et al., 2016). The authors also reported greater hamstrings interlimb asymmetry in concentric and eccentric strength in amateur players (Carvalho et al., 2016). Currently, limited evidence exists about the difference in muscle strength imbalances in soccer players of different performance levels or age (Carvalho et al., 2016; Croisier et al., 2008). Therefore, the aim of the present study was to compare quadriceps and hamstrings strength, the hamstrings-to-quadriceps ratio and inter-limb muscle asymmetry in professional, elite academy and amateur soccer players.

\section{Methods}

\section{Participants}

Two hundred-six soccer players ( professional $=75$, elite academy $=68$, amateur $=$ 63) volunteered for the present investigation. The anthropometrics for each group are reported in Table 1. Goalkeepers were excluded a priori from this study, as well as players who reported knee joint/muscle injuries in the previous year. The procedures were previously approved by the Ethics Committee of the University of Suffolk (Ipswich, UK) and conducted according to the Declaration of Helsinki (1975) for studies involving human subjects and in line with the ethical standards in sports and exercise science. No economic incentives were provided. Participants and the clubs' medical staffs were informed about the potential risks of the current procedures and provided written informed consent. Parental written consent was obtained from the minor participants.

\section{Study design}

The present investigation was designed as a cross-sectional study. Since no study has used a 
similar design with similar populations, an accurate a priori power calculation was not possible. However, using statistical software for power calculation (G-Power, Stuttgart, Germany), given the study design, the number of participants, a moderate effect size (ES) of the main factor, the number of groups and $\alpha=0.05$, an $a$ posteriori power calculation resulted in $1-\beta=0.91$.

Each participant was involved in two different testing sessions, separated by at least two days. During the first one, participants were familiarized with the isokinetic dynamometer and experienced each testing modality. During the second session, they were tested according to the same procedures used in the first session. Participants and the clubs were instructed to avoid any vigorous training session for the two days preceding the second testing session.

\section{Isokinetic measurements}

The quadriceps and hamstrings peak torque was measured using an isokinetic dynamometer (Cybex Norm, Ronkonkoma, USA). The device was calibrated and the gravity correction executed according to the manufacturer's procedures. The current procedures were conducted in line with previous research (Coratella and Bertinato, 2015; Coratella et al., 2015). Briefly, participants were secured to the seat (inclination: $85^{\circ}$ ) by a seatbelt and the knee was aligned to the centre of rotation. An additional seatbelt secured the tested limb, while the untested limb was immobilized by a lever. The upper limbs were crossed against the chest. After a standardized warm up consisting of separate 10 sub-maximal concentric and 10 submaximal eccentric repetitions for both quadriceps and hamstrings, peak torque was investigated at $60^{\circ} \cdot \mathrm{s}^{-1}$ in both concentric and eccentric modalities and at $300^{\circ} \cdot \mathrm{s}^{-1}$ in the concentric modality (van Dyk et al., 2016). Hamstrings and quadriceps were randomly tested at first, but the sets were performed from the slowest to the quickest velocity, first in the concentric and then in the eccentric modality (Rahnama et al., 2003). Three maximal repetitions for each modality were performed and the peak torque was measured and inserted into the data analysis. Two minutes of passive recovery separated each set. The operators provided strong verbal encouragement to the participants to maximally perform during each trial. Both preferred and non-preferred limbs were tested in randomized order, with the preferred limb defined as the one preferred to kick a ball.

The conventional $\mathrm{H}_{\text {conc: }} \mathrm{Q}_{\mathrm{conc}}$ and the functional $\mathrm{H}_{\text {ecc: }} \mathrm{Q}_{\text {conc }}$ ratio were then calculated and inserted into the data analysis (Coratella et al., 2015a, 2018a). In addition, the inter-limb asymmetry was calculated as follows (Coratella et al., 2018)

\section{Statistical analysis}

Asymmetry $=($ stronger $/$ weaker $) /$ stronger ${ }^{*} 100$.

Statistical analyses were performed using SPSS software version 20 for Windows 7, Chicago, USA. The Shapiro-Wilk test was used to check the normality assumption. Data were presented as mean \pm standard deviation (SD). Separate oneway analysis of variance (ANOVA) was employed to detect possible between-group differences in hamstrings and quadriceps peak torque, conventional $\mathrm{H}_{\text {conc: }} \mathrm{Q}_{\mathrm{conc}}$ and functional $H_{\text {ecc: }} Q_{\text {conc }}$ ratios in either a preferred or a nonpreferred limb and inter-limb hamstrings and quadriceps peak torque asymmetry (Hopkins et al., 2009). Post-hoc analysis was conducted using Bonferroni's adjustment. Significance was set at $p$ $<0.05$. Outcomes were expressed as a value with a $90 \%$ confidence interval (CI). Robust estimates of the CI (bias corrected and accelerated) and data distribution (heteroskedasticity assumption) were evaluated using the bootstrapping technique (randomly 1000 bootstrap samples). Effect size (ES) was calculated and interpreted as: trivial: < 0.20 , small: $0.20-0.59$, moderate: $0.60-1.19$, large: 1.20-1.99, and very large $\geq 2.00$ (Hopkins et al., 2009).

\section{Results}

Table 2 summarises the strength variables of professional, elite academy and amateur players. In the preferred limb, the main effect for the factor group was found in quadriceps concentric peak torque at $60^{\circ} \cdot \mathrm{s}^{-1}$ and $300^{\circ} \cdot \mathrm{s}^{-1}(\mathrm{~F}=$ 40.8, $p<0.001$, and $\mathrm{F}=36.5, p<0.001$, respectively), hamstrings concentric peak torque at $60^{\circ} \cdot \mathrm{s}^{-1}$ and $300^{\circ} \cdot \mathrm{s}^{-1}(\mathrm{~F}=37.6, p<0.001$, and $\mathrm{F}=$ 61.8, $p<0.001)$ and hamstrings eccentric peak torque at $60^{\circ} \cdot \mathrm{s}^{-1}(\mathrm{~F}=29.8, p<0.001)$. In the nonpreferred limb, the main effect for the factor group was found in the quadriceps concentric peak torque at $60^{\circ} \cdot \mathrm{s}^{-1}$ and $300^{\circ} \cdot \mathrm{s}^{-1}(\mathrm{~F}=60.7, p<$ 
0.001 and $\mathrm{F}=67.1, p<0.001$, respectively), hamstrings concentric peak torque at $60^{\circ} \cdot \mathrm{s}^{-1}$ and $300^{\circ} \cdot \mathrm{s}^{-1}(\mathrm{~F}=61.8, p<0.001$ and $\mathrm{F}=34.4, p<0.001)$ and hamstrings eccentric peak torque at $60^{\circ} \cdot \mathrm{s}^{-1}(\mathrm{~F}=$ 35.8, $p<0.001$ ).

Table 3 summarises the strength ratio variables of professional, elite academy and amateur players. In the preferred limb, the main effect for the factor group was found in the conventional $\mathrm{H}_{\text {conc }}: \mathrm{Q}_{\text {conc }}$ ratio at $60^{\circ} \cdot \mathrm{s}^{-1}(\mathrm{~F}=4.1, p=$ $0.017)$, but not at $300^{\circ} \cdot \mathrm{s}^{-1}(\mathrm{~F}=2.08, p=0.271)$. The main effect for the factor group was in the functional $\mathrm{H}_{\text {ecc: }} \mathrm{Q}_{\text {conc }}$ ratio in the preferred leg at $60^{\circ} \cdot \mathrm{s}^{-1}(\mathrm{~F}=3.1, p=0.047)$. In the non-preferred limb, the main effect for the factor group was found in the conventional $\mathrm{H}_{\text {conc: }} \mathrm{Q}_{\text {conc }}$ ratio at $60^{\circ} \cdot \mathrm{s}^{-1}$ $(\mathrm{F}=5.2, p=0.006)$ and $300^{\circ} \cdot \mathrm{s}^{-1}(\mathrm{~F}=7.04, p<0.001)$, but not in the functional Hecc: $\mathrm{Q}_{\text {conc }}$ ratio at $60^{\circ} \cdot \mathrm{s}^{-1}(\mathrm{~F}$ $=0.003, p=0.991$ ).

Table 4 summarises the inter-limb strength asymmetry in professional, elite academy and amateur players. The main effect for the factor group was found in the quadriceps inter-limb concentric peak torque asymmetry in quadriceps at $60^{\circ} \cdot \mathrm{s}^{-1}$ and $300^{\circ} \cdot \mathrm{s}^{-1}(\mathrm{~F}=8.1, p<0.001$, and $\mathrm{F}=14.7$, $p<0.001$, respectively), in hamstrings inter-limb concentric peak torque asymmetry at $60^{\circ} \cdot \mathrm{s}^{-1}$ and $300^{\circ} \cdot \mathrm{s}^{-1}(\mathrm{~F}=4.47, p=0.013$, and $\mathrm{F}=10.7, p<0.001$, respectively) and in hamstrings inter-limb eccentric peak torque asymmetry at $60^{\circ} \cdot \mathrm{s}^{-1}(\mathrm{~F}=3.2$, $p=0.040)$.

\section{Discussion}

The present study was the first to compare lower-limb muscle strength, anteriorposterior and inter-limb asymmetry in professional, elite academy and amateur soccer players. Greater (ES: moderate) quadriceps and hamstrings strength was found in professional compared to elite academy players; greater (ES: moderate to very large) quadriceps and hamstrings strength was found in professional compared to amateur players, while such a difference decreased between the elite academy and amateur players (ES trivial to moderate). A slightly higher (ES small) conventional Hconc:Qconc ratio was found in professional compared to elite academy players; such a difference was not observed in professional compared to amateur players (ES small in both directions), while amateur athletes had a higher (ES small to moderate) conventional Hconc:Qconc ratio than elite academy players. Overall, only a moderately higher functional Hecc:Qconc ratio was found in professional compared to elite academy players. Finally, while no difference in hamstrings and quadriceps inter-limb strength asymmetry was found in professional compared to elite academy players, greater quadriceps, but not hamstrings asymmetry was found in amateur compared to professional (ES small to large) and elite academy players (ES small to large).

\begin{tabular}{|c|c|c|c|}
\hline \multicolumn{4}{|c|}{$\begin{array}{c}\text { Summary of the demographics and anthropometrics for each group (players }=206 ; \\
\text { Professional }=75 ; \text { Elite academy }=68 ; \text { Amateur }=63) \text { is reported. } \\
\text { Data are presented as mean } \pm S D .\end{array}$} \\
\hline Group & Age (years) & Body mass (kg) & Height (m) \\
\hline Professional & $24 \pm 5$ & $79.5 \pm 7.9$ & $1.83 \pm 0.05$ \\
\hline Elite academy & $18 \pm 2$ & $74.4 \pm 8.0$ & $1.77 \pm 0.06$ \\
\hline Amateur & $20 \pm 3$ & $79.1 \pm 8.3$ & $1.79 \pm 0.06$ \\
\hline
\end{tabular}


Table 2

Summary of the quadriceps and hamstrings strength (players $=206$ : Professional $=75$, Elite academy $=68$, Amateur $=63$ ) measures is reported. Data are presented as mean $\pm S D$ and differences in mean with $90 \% C I$. Effect size and its interpretation are provided.

\begin{tabular}{|c|c|c|c|c|c|c|}
\hline & $\begin{array}{l}\text { Professional } \\
(\mathrm{N} \cdot \mathrm{m})\end{array}$ & $\begin{array}{c}\text { Elite academy } \\
(\mathrm{N} \cdot \mathrm{m})\end{array}$ & $\begin{array}{l}\text { Amateur } \\
(\mathrm{N} \cdot \mathrm{m})\end{array}$ & $\begin{array}{c}\text { Difference P-E } \\
(90 \% \mathrm{CI}) \\
\mathrm{ES} \\
\text { (interpretation) } \\
\end{array}$ & $\begin{array}{c}\text { Difference P-A } \\
(90 \% \mathrm{CI}) \\
\text { ES } \\
\text { (interpretation) } \\
\end{array}$ & $\begin{array}{c}\text { Difference E-A } \\
(90 \% \mathrm{CI}) \\
\mathrm{ES} \\
\text { (interpretation) } \\
\end{array}$ \\
\hline \multicolumn{7}{|l|}{$\begin{array}{c}\text { Concentric } \\
\text { quadriceps } \\
(\mathrm{N} \cdot \mathrm{m})\end{array}$} \\
\hline $\operatorname{Pr}\left(60^{\circ} \cdot \mathrm{s}^{-1}\right)$ & $283.2 \pm 47.3$ & $241.9 \pm 38.2$ & $219.6 \pm 39.5$ & $\begin{array}{c}41.2(27.3 ; 55.1)^{*} \\
1.08(\text { moderate })\end{array}$ & $\begin{array}{c}63.5(49.3 ; 77.5)^{*} \\
1.66(\text { large })\end{array}$ & $\begin{array}{c}22.3(7.8 ; 36.9)^{*} \\
0.58(\text { small })\end{array}$ \\
\hline $\operatorname{NPr}\left(60^{\circ} \cdot \mathrm{s}^{-1}\right)$ & $282.5 \pm 49.8$ & $243.1 \pm 39.7$ & $198.3 \pm 43.1$ & $\begin{array}{c}39.3(24.5 ; 54.1)^{*} \\
1.04(\text { moderate })\end{array}$ & $\begin{array}{l}84.1(69.1 ; 99.1)^{*} \\
2.21 \text { (very large) }\end{array}$ & $\begin{array}{c}44.8(29.4 ; 60.3)^{*} \\
1.18(\text { moderate })\end{array}$ \\
\hline $\operatorname{Pr}\left(300^{\circ} \cdot \mathrm{s}^{-1}\right)$ & $145.5 \pm 22.1$ & $125.4 \pm 18.9$ & $118.1 \pm 17.4$ & $\begin{array}{c}20.19(13.7 ; 26.7)^{*} \\
0.97 \text { (moderate) }\end{array}$ & $\begin{array}{c}27.4(20.7 ; 34.1)^{*} \\
1.30 \text { (large })\end{array}$ & $\begin{array}{l}7.2(0.4 ; 14)^{*} \\
0.35(\text { small })\end{array}$ \\
\hline $\operatorname{NPr}\left(300^{\circ} \cdot \mathrm{s}^{-1}\right)$ & $143.1 \pm 22.6$ & $125.6 \pm 17.7$ & $103.7 \pm 18.6$ & $\begin{array}{l}17.5(10.9 ; 24.1)^{*} \\
0.84(\text { moderate })\end{array}$ & $\begin{array}{l}39.4(32.7 ; 46.1)^{*} \\
2.04(\text { very large })\end{array}$ & $\begin{array}{r}21.9(15.0 ; 28.7)^{*} \\
1.09 \text { (moderate })^{*}\end{array}$ \\
\hline \multicolumn{7}{|l|}{$\begin{array}{c}\text { Concentric } \\
\text { hamstrings } \\
(\mathrm{N} \cdot \mathrm{m})\end{array}$} \\
\hline $\operatorname{Pr}\left(60^{\circ} \cdot \mathrm{s}^{-1}\right)$ & $174.4 \pm 41.1$ & $136.3 \pm 27.3$ & $129.2 \pm 26.1$ & $\begin{array}{c}37.6(26.7 ; 48.3)^{*} \\
1.10(\text { moderate })\end{array}$ & $\begin{array}{c}44.7(33.5 ; 55.8)^{*} \\
1.18(\text { moderate })\end{array}$ & $\begin{array}{c}7.0(-4.3 ; 18.4) \\
0.21 \text { (small) }\end{array}$ \\
\hline $\operatorname{NPr}\left(60^{\circ} \cdot \mathrm{s}^{-1}\right)$ & $168.2 \pm 36.4$ & $132.6 \pm 24.3$ & $113.4 \pm 25.2$ & $\begin{array}{c}35.6(25.8 ; 45.4)^{*} \\
1.16(\text { moderate })\end{array}$ & $\begin{array}{c}54.8(44.5 ; 64.8)^{*} \\
1.52 \text { (large) }\end{array}$ & $\begin{array}{l}19.2(9.9 ; 24.3)^{*} \\
0.64(\text { moderate })\end{array}$ \\
\hline $\operatorname{Pr}\left(300^{\circ} \cdot \mathrm{s}^{-1}\right)$ & $97.8 \pm 18.4$ & $81.9 \pm 14.4$ & $82.2 \pm 18.5$ & $\begin{array}{c}15.8(10.2 ; 21.5)^{*} \\
1.06 \text { (moderate })^{*}\end{array}$ & $\begin{array}{l}15.5(9.7 ; 21.4)^{*} \\
1.04(\text { moderate })\end{array}$ & $\begin{array}{c}-0.3(-6.3 ; 5.6) \\
0.01(\text { trivial })\end{array}$ \\
\hline $\operatorname{NPr}\left(300^{\circ} \cdot \mathrm{s}^{-1}\right)$ & $96.2 \pm 16.98$ & $78.5 \pm 13.2$ & $72.9 \pm 18.7$ & $\begin{array}{l}17.7(12.2 ; 23.1)^{*} \\
1.18 \text { (moderate) }^{*}\end{array}$ & $\begin{array}{c}23.3(17.7 ; 28.8)^{*} \\
1.55 \text { (large })\end{array}$ & $\begin{array}{c}5.5(-0.1 ; 11.3) \\
0.37 \text { (small) }\end{array}$ \\
\hline \multicolumn{7}{|l|}{$\begin{array}{l}\text { Eccentric } \\
\text { hamstrings } \\
(\mathrm{N} \cdot \mathrm{m})\end{array}$} \\
\hline $\operatorname{Pr}\left(60^{\circ} \cdot \mathrm{s}^{-1}\right)$ & $218.1 \pm 66.4$ & $177.8 \pm 35.4$ & $150.7 \pm 32.7$ & $\begin{array}{c}40.2(17.7 ; 63.3)^{*} \\
0.76(\text { small })\end{array}$ & $\begin{array}{c}67.3(49.9 ; 84.6)^{*} \\
1.57 \text { (large) }\end{array}$ & $\begin{array}{c}27.0(3.4 ; 50.7)^{*} \\
0.79 \text { (small) }\end{array}$ \\
\hline $\operatorname{NPr}\left(60^{\circ} \cdot \mathrm{s}^{-1}\right)$ & $208.8 \pm 57.9$ & $176.5 \pm 39.1$ & $142.6 \pm 28.3$ & $\begin{array}{c}32.4(11.8 ; 52.4)^{*} \\
0.80(\text { moderate })\end{array}$ & $\begin{array}{c}66.4(50.7 ; 81.5)^{*} \\
1.75(\text { large })\end{array}$ & $\begin{array}{c}33.8(12.8 ; 54.9)^{*} \\
0.90(\text { moderate })\end{array}$ \\
\hline
\end{tabular}

$\operatorname{Pr}=$ Preferred; $N P r=$ Non-preferred; $S D=$ Standard deviation $C I=$ Confidence intervals; $P=$ Professional $E=$ Elite academy; $A=$ Amateur; $E S=$ Effect size $;{ }^{*}=p<0.05$. 
Table 3

Summary of the conventional $H_{\text {conc: }} Q_{\text {conc }}$ and functional $H_{\text {ecc: }} Q_{\text {conc }}$ ratio is shown (players $=206$ :

Professional $=75$; Elite academy $=68 ;$ Amateurs $=63$ ). Data are presented as mean $\pm S D$, and differences in $90 \% \mathrm{CI}$. Effect size and its interpretation are provided.

\begin{tabular}{|c|c|c|c|c|c|c|}
\hline & $\begin{array}{l}\text { Pro } \\
\text { (A.U.) }\end{array}$ & $\begin{array}{l}\text { Elite } \\
\text { young } \\
\text { (A.U.) }\end{array}$ & $\begin{array}{l}\text { Amateur } \\
\text { (A.U.) }\end{array}$ & $\begin{array}{c}\text { Difference P-E } \\
(90 \% \mathrm{CI}) \\
\mathrm{ES} \\
\text { (interpretation) }\end{array}$ & $\begin{array}{c}\text { Difference P-A } \\
(90 \% \mathrm{CI}) \\
\mathrm{ES} \\
\text { (interpretation) }\end{array}$ & $\begin{array}{c}\text { Difference E-A } \\
(90 \% \mathrm{CI}) \\
\mathrm{ES} \\
\text { (interpretation) }\end{array}$ \\
\hline \multicolumn{7}{|l|}{$\begin{array}{l}\text { Conventional } \\
\text { ratio }\end{array}$} \\
\hline $\begin{array}{c}\operatorname{Pr} \\
\left(60^{\circ} \cdot \mathrm{s}^{-1}\right)\end{array}$ & $0.61 \pm 0.10$ & $0.56 \pm 0.10$ & $0.58 \pm 0.06$ & $\begin{array}{c}0.04 \\
(0.01 ; 0.07)^{*} \\
0.52(\text { small })\end{array}$ & $\begin{array}{c}0.02 \\
(-0.01 ; 0.05) \\
0.34 \text { (small) }\end{array}$ & $\begin{array}{c}-0.02 \\
(-0.05 ; 0.01) \\
0.25 \text { (small) }\end{array}$ \\
\hline $\begin{array}{l}\mathrm{NPr} \\
\left(60^{\circ} \cdot \mathrm{s}^{-1}\right)\end{array}$ & $0.59 \pm 0.07$ & $0.55 \pm 0.09$ & $0.57 \pm 0.07$ & $\begin{array}{c}0.04 \\
(0.01 ; 0.06)^{*} \\
0.44(\text { small })\end{array}$ & $\begin{array}{c}0.02 \\
(-0.01 ; 0.04) \\
0.22(\text { small })\end{array}$ & $\begin{array}{c}-0.02 \\
(-0.05 ; 0.01) \\
0.22(\text { small })\end{array}$ \\
\hline $\begin{array}{c}\operatorname{Pr} \\
\left(300^{\circ} \cdot \mathrm{s}^{-1}\right)\end{array}$ & $0.67 \pm 0.10$ & $0.65 \pm 0.10$ & $0.69 \pm 0.11$ & $\begin{array}{c}0.01 \\
(-0.05 ; 0.18) \\
0.20 \text { (small) }\end{array}$ & $\begin{array}{c}-0.02 \\
(-0.05 ; 0.01) \\
0.20(\text { small })\end{array}$ & $\begin{array}{c}-0.04 \\
(-0.07 ;-0.01)^{*} \\
0.40(\text { small })\end{array}$ \\
\hline $\begin{array}{c}\mathrm{NPr} \\
\left(300^{\circ} \cdot \mathrm{S}^{-1}\right)\end{array}$ & $0.66 \pm 0.12$ & $0.62 \pm 0.09$ & $0.70 \pm 0.14$ & $\begin{array}{c}0.04 \\
(0.01 ; 0.08)^{*} \\
0.40(\text { small })\end{array}$ & $\begin{array}{c}-0.04 \\
(-0.01 ; 0.01) \\
0.40(\text { small })\end{array}$ & $\begin{array}{c}-0.07 \\
(-0.11 ;-0.04)^{*} \\
0.80(\text { moderate })\end{array}$ \\
\hline \multicolumn{7}{|l|}{$\begin{array}{l}\text { Functional } \\
\text { ratio }\end{array}$} \\
\hline $\begin{array}{c}\operatorname{Pr} \\
\left(60^{\circ} \cdot \mathrm{s}^{-1}\right)\end{array}$ & $0.72 \pm 0.10$ & $0.76 \pm 0.16$ & $0.70 \pm 0.15$ & $\begin{array}{c}0.04 \\
(-0.03 ;-0.1) \\
0.44(\text { small })\end{array}$ & $\begin{array}{c}0.06 \\
(0.01 ; 0.11)^{*} \\
0.66(\text { moderate })\end{array}$ & $\begin{array}{c}0.03 \\
(-0.04 ; 0.09) \\
0.22 \text { (small) }\end{array}$ \\
\hline $\begin{array}{l}\mathrm{NPr} \\
\left(60^{\circ} \cdot \mathrm{s}^{-1}\right)\end{array}$ & $0.73 \pm 0.10$ & $0.73 \pm 0.12$ & $0.73 \pm 0.13$ & $\begin{array}{c}0.01 \\
(0.06 ; 0.06) \\
0.01 \text { (trivial) }\end{array}$ & $\begin{array}{c}0.01 \\
(-0.04 ; 0.04) \\
0.01 \text { (trivial) }\end{array}$ & $\begin{array}{c}0.01 \\
(-0.06 ; 0.06) \\
0.01 \text { (trivial) }\end{array}$ \\
\hline
\end{tabular}

$P r=$ Preferred; $N P r=$ Non-preferred; $S D=$ Standard deviation $C I=$ Confidence intervals; $P=$ Professional; $E=$ Elite academy; $A=$ Amateur $E S=$ Effect size; ${ }^{*}=p<0.05$. 


\section{Table 4}

Summary of the inter-limb asymmetry (players $=206$ : Professional $=75$, Elite academy $=68$, Amateurs $=63$ ), shown as the difference between the stronger and the weaker lower-limb.

Data are presented as mean $\pm S D$, and differences in mean with $90 \% \mathrm{CI}$.

Effect size and its interpretation are provided.

\begin{tabular}{|c|c|c|c|c|c|c|}
\hline Variable & $\begin{array}{l}\text { Pro } \\
(\%)\end{array}$ & $\begin{array}{c}\text { Elite } \\
\text { young } \\
(\%)\end{array}$ & $\begin{array}{c}\text { Amateur } \\
(\%)\end{array}$ & $\begin{array}{c}\text { Difference P-E } \\
(90 \% \mathrm{CI}) \\
\mathrm{ES} \\
\text { (interpretation) } \\
\end{array}$ & $\begin{array}{c}\text { Difference P-A } \\
(90 \% \mathrm{CI}) \\
\text { ES } \\
\text { (interpretation) } \\
\end{array}$ & $\begin{array}{c}\text { Difference E-A } \\
(90 \% \mathrm{CI}) \\
\mathrm{ES} \\
\text { (interpretation) } \\
\end{array}$ \\
\hline \multirow{3}{*}{$\begin{array}{c}\text { Concentric } \\
\text { quadriceps } \\
\left(60^{\circ} \cdot \mathrm{s}^{-1}\right)\end{array}$} & & & & & & \\
\hline & & & & & $-5.1(-7.4 ;-2.6)^{*}$ & $-1.5(-4.6 ; 1.6)$ \\
\hline & $6.4 \pm 6.2$ & $9.9 \pm 7.7$ & $11.5 \pm 8.7$ & $\begin{array}{c}-3.5(-6.4 ; 0.9) \\
0.43(\text { small })\end{array}$ & 0.67 (large) & 0.20 (small) \\
\hline$\left(300^{\circ} \cdot \mathrm{s}^{-1}\right)$ & $6.3 \pm 4.7$ & $7.8 \pm 5.4$ & $12.1 \pm 8.1$ & $\begin{array}{c}-1.4(-3.5 ; 0.43) \\
0.29 \text { (small) }\end{array}$ & $\begin{array}{c}-5.8(-7.6 ;-4.0)^{*} \\
0.87(\text { large })\end{array}$ & $\begin{array}{c}-4.3(-6.7 ;-1.9)^{*} \\
0.62(\text { large })\end{array}$ \\
\hline
\end{tabular}

Concentric

hamstrings

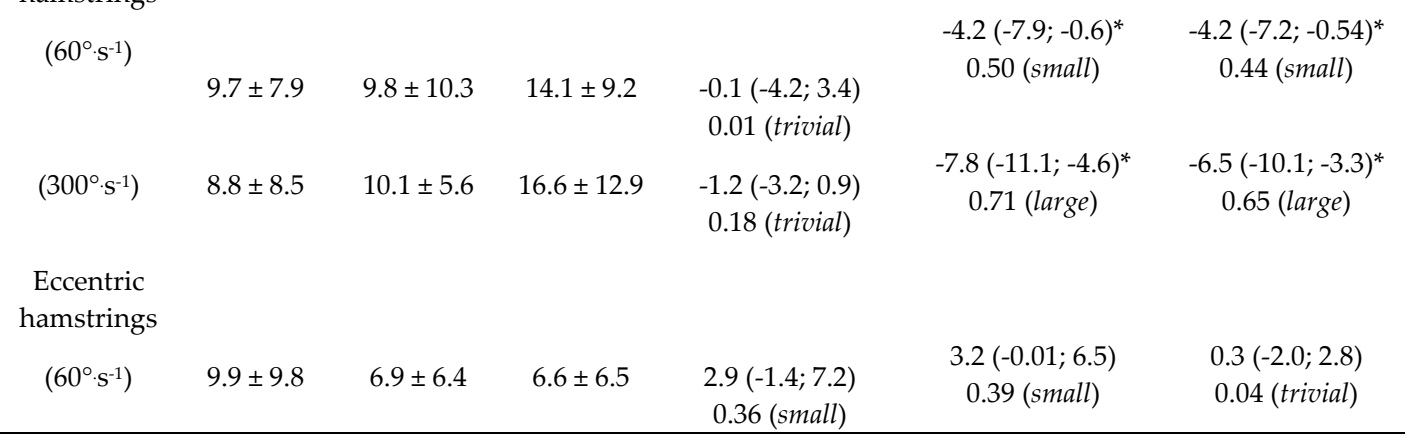

$S D=$ Standard deviation $; C I=$ Confidence intervals $P=$ Professional;

$E=$ Elite academy; $A=$ Amateur $;$ ES $=$ Effect size; ${ }^{*}=p<0.05$.

Professional players have higher hamstrings and quadriceps strength compared to elite academy and amateur players. This difference in strength occurred in both quadriceps and hamstrings, at both 60 .s- 1 and 300 .s-1 as well as in both the concentric and eccentric modality. The present results agree with previous evidence, which reported higher quadriceps concentric and hamstrings concentric and eccentric peak torque in first-division $(258,156$ and 181 N.m, respectively) compared to second- division players (234, 138 and 164 N.m, respectively) (Carvalho et al., 2016). A recent study reported quadriceps and hamstrings concentric peak torque (60 .s-1) equal to 227 and 122 N.m in semi-professional players, which were lower values than those found in professional and elite academy players enrolled in the current study (Lee et al., 2017). Moreover, strength variables reported here for elite academy and amateur players are higher and equivalent, respectively, to young amateur players' 
quadriceps concentric (217 N.m) and hamstrings concentric and eccentric peak torque (136 and 150 N.m, respectively) (Thomas et al., 2017). Similar lower-limb muscle strength was reported in amateur soccer players (quadriceps and hamstring concentric peak torque of 215 and 152 N.m, respectively) (Ali and Williams, 2013). Previous studies have reported that lower-limb muscle strength is correlated with several soccerrelated abilities. For example, lower COD performance time was negatively correlated to greater quadriceps and hamstrings strength (Jones et al., 2009). Similarly, quadriceps and hamstrings strength was positively correlated with COD performance, since the ability to accelerate and decelerate the body mass requires both quadriceps and hamstrings to exert maximal strength continuously (Chaouachi et al., 2012). Moreover, lower-limb muscle strength was correlated with jumping or sprinting ability (Comfort et al., 2014; Wisløff et al., 2004), with hamstrings playing a key role in the horizontal propulsion action during sprinting (Morin et al., 2015). On the other hand, hamstring weakness increases its susceptibility to tears and strains (Timmins et al., 2016). Coupled with muscle weakness, age was shown to increase the hamstrings injury risk, given the lower incidence in 17-22 year olds than in older players (Freckleton and Pizzari, 2013). Thus, increasing hamstrings strength may help counteract the negative effects of muscle weakness and age on the hamstrings injury risk.

Both the conventional Hconc:Qconc and functional Hecc:Qconc (Orchard et al., 1997) ratios have been created to monitor the hamstrings strain injury risk. Their rationale is that hamstrings should counteract the force exerted by quadriceps to avoid occurring of over-elongation. Moreover, hamstrings assist the anterior cruciate ligament in preventing anterior drawer forces, as well as decelerate the leg prior to full extension and thus limiting the knee overextension (Croisier et al., 2008; Carvalho et al., 2016). However, a recent meta-analysis questioned the hamstrings injury prediction from low hamstrings-toquadriceps values (Green et al., 2018). Indeed, while an association in the functional Hecc:Qconc ratio was found in sprinters (Yeung et al., 2009), no such an association was reported in Australian soccer players (Bennell et al., 1998). With the exception of the moderately greater functional Hecc:Qconc ratio in the preferred limb in professional vs. amateur soccer players, no other difference was observed here. This may be due to the larger difference in quadriceps than in hamstrings strength between the two populations. It could be argued that the preferred quadriceps are used to kick the ball and to perform COD effectively (Rouissi et al., 2016), although the tasks are not forcibly correlated with each other. However, the longer training experience might have led professional players to such a specific adaptation. The present data agree with values of the conventional Hconc:Qconc ratio reported previously in the literature, which ranges between 0.53 and 0.82 for professional soccer players (Baroni et al., 2018). Additionally, conventional Hconc:Qconc and functional Hecc:Qconc ratios equal to 0.62 and 0.69 , respectively, were observed in amateur team sports players (Thomas et al., 2017) and equal to 0.62 and 0.71 , respectively, in first-division soccer players, as well as equal to 0.59 and 0.71 , respectively, in second-division soccer players (Carvalho et al., 2016). In contrast, a recent study has reported no difference in the conventional Hconc:Qconc ratio in professional, amateur and university soccer players $(0.64,0.64$ and 0.60, respectively) (Jeon et al., 2016). Given the hamstrings-injury multifactorial origin, factors like age, previous injuries history and strength should be included (Ekstrand et al., 2016). Age has consistently been identified as a risk factor for a hamstring injury, and a recent study has observed a $7 \%$ increased risk of a hamstring injury with each additional year (van Dyk et al., 2017). However, such a parameter is classified as a non-modifiable risk factor. Therefore, more attention should be dedicated to the modifiable risk factors that have previously shown relationships with injuries, such as previous injuries or training loads (Ekstrand et al., 2016; Hägglund et al., 2013; Malone et al., 2019). Lowerlimb muscle strength and strength imbalances could have a key role in the development of preventive strategies in soccer (Croisier et al., 2008). It was suggested that a functional Hecc:Qconc ratio lower than 0.7 might result in an increased risk of hamstrings becoming overelongated due to the greater strength in the quadriceps (Rahnama et al., 2003). Notwithstanding, in light of previous outcomes, 
caution should be used when correlating the functional Hecc:Qconc ratio and the hamstrings strain injury risk (van Dyk et al., 2016). The present findings also suggest that the hamstringsto-quadriceps ratio offers limited possibility to differentiate between the soccer players' level and performance.

The present outcomes showed that the overall inter-limb strength asymmetry was lower in professional compared to elite academy and amateur players. The role of inter-limb strength asymmetry in the lower limb injury prevention is not clear. In a recent meta-analysis (Green et al., 2018) and a cohort study (Jeon et al., 2016), the hamstrings inter-limb asymmetry was shown to play a reduced role in predicting hamstrings injury risk. Nevertheless, it was reported previously that the inter-limb hamstrings eccentric strength asymmetry was predictive of the hamstrings strain-type injury risk (Freckleton and Pizzari, 2013). Additionally, a reduced quadriceps inter-limb strength asymmetry is essential for a safe return to the sport after injury (Ithurburn et al., 2015; Schmitt et al., 2015). Interestingly, hamstrings and quadriceps interlimb strength asymmetry was recently shown to be negatively correlated with COD and sprinting ability (Coratella et al., 2018). Those authors reported that increasing the inter-limb asymmetry decreased the COD and sprint performance, with no impact on jumping ability. This could be due to the key role of both hamstrings and quadriceps in stabilizing, braking and accelerating the body during COD and a sprint (Morin et al., 2015; Rouissi et al., 2016), while the stronger limb seems to compensate for the work of the weaker limb in jumping ability (Yoshioka et al., 2011). In the literature, an inter-limb hamstrings strength deficit threshold less than $10-15 \%$ is recommended (Thomas et al., 2017; Ruas et al., 2015). The findings presented in the current study agree with the differences (range 9-12\%) found in quadriceps and hamstrings inter-limb strength in collegiate athletes (Jones and Bampouras, 2010). Additionally, a previous investigation found hamstrings bilateral asymmetry equal to $9 \%$ in professional soccer players, $8 \%$ in physically active men and $7 \%$ in amateur team sports players (Impellizzeri et al., 2008). These results are of interest because players with inter-limb strength imbalance are 4 to 5 times more likely to sustain a hamstring injury when compared with a balanced inter-limb strength group (Croisier et al., 2008). Thus, monitoring hamstrings and quadriceps isokinetic strength asymmetry over time might be of help to check eventual repercussion on performance or injury risk.

Some limitations accompany the present investigation. This study provides normative data about soccer-specific populations, but it does not provide evidence of the capacity of the isokinetic lower-limb muscle strength assessment to predict soccer players' injuries. Furthermore, it is acknowledged that the cost and availability of an isokinetic dynamometer constitutes a major limitation considering the feasibility and the reproducibility of the present procedures and consequences of their interpretation. Additionally, the isokinetic dynamometer allows a single-joint movement only to be assessed, limiting the inference on the complex multi-joint activities performed in soccer.

\section{Conclusions}

The present findings provide coaches and medical staff with normative data about the specific populations involved. A periodic screening could be useful to evaluate both the total lower-limb muscle strength and the interlimb strength asymmetry, which showed possible usefulness to monitor the injury risk and soccer players' performance in the COD and sprints. Additionally, athletes returning to sport after injury should include an inter-limb strength evaluation to check the status of the injured limb. The hamstrings-to-quadriceps ratio offers limited capacity to differentiate between the soccer players' level and performance. Lastly, since the present investigation included professional players, normative strength data might indicate to the sub-elite population the desired quadriceps and hamstrings strength level. 


\section{References}

Ali A, Williams C. Isokinetic and isometric muscle function of the knee extensors and flexors during simulated soccer activity: effect of exercise and dehydration. J Sports Sci, 2013: 31: 907-916. https://doi.org/10.1080/02640414.2012.753635

Baroni BM, Ruas C V, Ribeiro-Alvares JB, Silveira Pinto R. Hamstrings-to-quadriceps torque ratios of professional male soccer players: a systematic review. J Strength Cond Res, 2018; 1-13. https://doi.org/10.1519/JSC.0000000000002609

Bennell K, Wajswelner H, Lew P, Schall-Riaucour A, Leslie S, Plant D, and Cirone J. Isokinetic strength testing does not predict hamstring injury in Australian Rules footballers. Br J Sports Med, 1988; 32: 309314

Carvalho A, Brown S, Abade E. Evaluating injury risk in first and second league professional Portuguese soccer: muscular strength and asymmetry. J Hum Kinet, 2016; 51:19-26. https://doi.org/10.1515/hukin2015-0166

Chaouachi A, Manzi V, Chaalali A, Wong DP, Chamari K, Castagna C. Determinants analysis of change-ofdirection ability in elite soccer players. J Strength Cond Res, 2012; 26:2667-2676. https://doi.org/10.1519/JSC.0b013e318242f97a

Comfort P, Stewart A, Bloom L, Clarkson B. Relationship between strength, sprint and jump performance in well trained youth soccer players. J Strength Cond Res, 2014; 28: 173-177. https://doi.org/10.1519/JSC.0b013e318291b8c7

Coratella G, Beato M, Milanese C, Longo S, Limonta E, Rampichini S, Cè E, Bisconti AV, Schena F, Esposito F. Specific Adaptations in Performance and Muscle Architecture After Weighted Jump-Squat vs Body Mass Squat Jump Training in Recreational Soccer Players. J Strength Cond Res, 2018a; 32: 921-929. https://doi.org/10.1519/JSC.0000000000002463

Coratella G, Beato M, Schena F. Correlation between quadriceps and hamstrings inter-limb strength asymmetry with change of direction and sprint in U21 elite soccer- players. Hum Mov Sci, 2018b; 59: 8187. https://doi.org/10.1016/j.humov.2018.03.016

Coratella G, Bellin G, Beato M, Schena F. Fatigue affects peak joint torque angle in hamstrings but not in quadriceps. J Sports Sci, 2015a; 33: 1276-82. https://doi.org/10.1080/02640414.2014.986185

Coratella G, Milanese C, Schena F. Unilateral eccentric resistance training: a direct comparison between isokinetic and dynamic constant external resistance modalities. Eur J Sport Sci,2015b; 15: 720-6. https://doi.org/10.1080/17461391.2015.1060264

Croisier J-L, Ganteaume S, Binet J, Genty M, Ferret JM. Strength imbalances and prevention of hamstring injury in professional soccer players: a prospective study. Am J Sports Med, 2008; 36: 1469-75. https://doi.org/10.1177/0363546508316764

Ekstrand J, Waldén M, Hägglund M. Hamstring injuries have increased by $4 \%$ annually in men's professional football, since 2001: a 13-year longitudinal analysis of the UEFA Elite Club injury study. $\mathrm{Br}$ J Sports Med, 2016; 50: 731-737. https://doi.org/10.1136/bjsports-2015-095359

Freckleton G, Pizzari T. Risk factors for hamstring muscle strain injury in sport: A systematic review and meta-analysis. Br J Sports Med, 2013; 47: 351-358. https://doi.org/10.1136/bjsports-2011-090664

Green B, Bourne MN, Pizzari T. Isokinetic strength assessment offers limited predictive validity for detecting risk of future hamstring strain in sport: a systematic review and meta-analysis. Br J Sports Med, 2018; 52:329-336. https://doi.org/10.1136/bjsports-2017-098101

Hägglund M, Waldén M, Ekstrand J. Risk Factors for Lower Extremity Muscle Injury in Professional Soccer. Am J Sports Med, 2013; 41: 327-335. https://doi.org/10.1177/0363546512470634

Heiser TM, Weber J, Sullivan G, Clare P, Jacobs RR. Prophylaxis and management of hamstring muscle injuries in intercollegiate football players. Am J Sports Med, 1984 12:368-370. https://doi.org/10.1177/036354658401200506

Hopkins WG, Marshall SW, Batterham AM, Hanin J. Progressive Statistics for Studies in Sports Medicine and Exercise Science. Med Sci Sport Exerc, 2009; 41: 3-13. https://doi.org/10.1249/MSS.0b013e31818cb278

Impellizzeri FM, Bizzini M, Rampinini E, Cereda F, Maffiuletti NA. Reliability of isokinetic strength imbalance ratios measured using the Cybex NORM dynamometer. Clin Physiol Funct Imaging, 2009; 
28:113-119. https://doi.org/10.1111/j.1475-097X.2007.00786.x

Ithurburn MP, Paterno MV, Ford KR, Hewett TE, Schmitt LC. Young Athletes With Quadriceps Femoris Strength Asymmetry at Return to Sport After Anterior Cruciate Ligament Reconstruction Demonstrate Asymmetric Single-Leg Drop-Landing Mechanics. Am J Sports Med, 2015; 43: 2727-2737. https://doi.org/10.1177/0363546515602016

Jeon K, Chun S, Seo B. Effects of muscle strength asymmetry between left and right on isokinetic strength of the knee and ankle joints depending on athletic performance level. J Phys Ther Sci, 2016 28:1289-1293. https://doi.org/10.1589/jpts.28.1289

Jones PA, Bampouras TM. A comparison of isokinetic and functional methods of assessing bilateral strength imbalance. J Strength Cond Res, 2010; 24: 1553-1538. https://doi.org/10.1519/JSC.0b013e3181dc4392

Jones PA, Bampuras TM, Marrin K. An Investigation Into the Physical Determinants of Change of Direction Speed. J Sports Med Phys Fitness, 2009; 49:97-104

Lee JWY, Mok K-M, Chan HCK, Yung PSH, Chan KM. Eccentric hamstring strength deficit and poor hamstring-to-quadriceps ratio are risk factors for hamstring strain injury in football: A prospective study of 146 professional players. J Sci Med Sport, 2018; 8: 789-793. https://doi.org/10.1016/j.jsams.2017.11.017

Malone S, Hughes B, Doran DA, Collins K, Gabbett TJ. Can the workload-injury relationship be moderated by improved strength, speed and repeated-sprint qualities? J Sci Med Sport, 2019 22:29-34. https://doi.org/10.1016/j.jsams.2018.01.010

Morin J-B, Gimenez P, Edouard P, Arnal P, Jiménez-Reyes P, Samozino P, Brughelli M, Mendiguchia J. Sprint Acceleration Mechanics: The Major Role of Hamstrings in Horizontal Force Production. Front Physiol, 2015; 6: https://doi.org/10.3389/fphys.2015.00404

Orchard J, Marsden J, Lord S, Garlick D. Preseason hamstring muscle weakness associated with hamstring muscle injury in Australian footballers. Am $J$ Sports Med, 1997; 25: 81-5. https://doi.org/10.1177/036354659702500116

Rahnama N, Reilly T, Lees A, Graham-Smith P. Muscle fatigue induced by exercise simulating the work rate of competitive soccer. J Sports Sci, 2003; 21: 933-942. https://doi.org/10.1080/0264041031000140428

Rodriguez-Rosell D, Mora-Custodio R, Franco-Márquez F, Yáñez-García JM, González-Badillo JJ. Traditional vs. sport-specific vertical jump tests: reliability, validity and relationship with the legs strength and sprint performance in adult and teen soccer and basketball players. J strength Cond Res, 2017; 31: 196206. https://doi.org/10.1519/JSC.0000000000001476

Rouissi M, Chtara M, Owen A, Chaalali A, Chaouachi A, Gabbett T, Chamari K. Effect of leg dominance on change of direction ability amongst young elite soccer players. J Sports Sci, 2016; 34: 542-548. https://doi.org/10.1080/02640414.2015.1129432

Ruas CV, Minozzo F, Pinto MD, Brown LE, Pinto RS. Lower-extremity strength ratios of professional soccer players according to field position. J Strength Cond Res, 2015; 29: 1220-1226. https://doi.org/10.1519/JSC.0000000000000766

Schmitt LC, Paterno M V., Ford KR, Myer GD, Hewett TE. Strength Asymmetry and Landing Mechanics at Return to Sport after Anterior Cruciate Ligament Reconstruction. Med Sci Sport Exerc, 2015; 47:14261434. https://doi.org/10.1249/MSS.0000000000000560

Thomas C, Comfort P, Dos'Santos T, Jones P. Determining Bilateral Strength Imbalances in Youth Basketball Athletes. Int J Sports Med, 2017; 38: 683-690. https://doi.org/10.1055/s-0043-112340

Timmins RG, Bourne MN, Shield AJ, Williams MD, Lorenzen C, Opar DA. Short biceps femoris fascicles and eccentric knee flexor weakness increase the risk of hamstring injury in elite football (soccer): A prospective cohort study. Br J Sports Med, 2016; 50: 1524-1535. https://doi.org/10.1136/bjsports-2015095362

van Dyk N, Bahr R, Burnett AF, Whiteley R, Bakken A, Mosler A, Farooq A, Witvrouw E. A comprehensive strength testing protocol offers no clinical value in predicting risk of hamstring injury: a prospective cohort study of 413 professional football players. Br J Sports Med, 2017; 51: 1695-1702. https://doi.org/10.1136/bjsports-2017-097754 
van Dyk N, Bahr R, Whiteley R, Kumar BD, Hamilton B, Farooq A, Witvrouw E. Hamstring and Quadriceps Isokinetic Strength Deficits Are Weak Risk Factors for Hamstring Strain Injuries. Am J Sports Med, 2016; 44: 1789-1795. https://doi.org/10.1177/0363546516632526

Weiss K, Whatman C. Biomechanics Associated with Patellofemoral Pain and ACL Injuries in Sports. Sport Med, 2015; 45: 1325-1337. https://doi.org/10.1007/s40279-015-0353-4

Wisløff U, Castagna C, Helgerud J, Jones R, Hoff J. Strong correlation of maximal squat strength with sprint performance and vertical jump height in elite soccer players. Br J Sports Med, 2004; 38:285-288

Yeung SS, Suen AMY, Yeung EW. A prospective cohort study of hamstring injuries in competitive sprinters: preseason muscle imbalance as a possible risk factor. Br J Sports Med, 2009; 43: 589-94. https://doi.org/10.1136/bjsm.2008.056283

Yoshioka S, Nagano A, Hay DC, Fukashiro S. The effect of bilateral asymmetry of muscle strength on the height of a squat jump: A computer simulation study. J Sports Sci, 2011; 29: 867-877. https://doi.org/10.1080/02640414.2011.568512

\section{Corresponding author:}

\section{Marco Beato,}

School of Health and Sports Sciences,

University of Suffolk, Ipswich, UK.

E-mail: M.Beato@uos.ac.uk 